\title{
VuInerability and Resilience
}

\author{
Heiderose Kilper
}

(C) Springer-Verlag 2012

Perceiving and dealing with endangerment is part of the history of human societies. People have always attempted to protect themselves from the threats that they perceive. It is, however, possible to identify differences in the ways in which endangerment is handled. Exactly what is defined as a threat, the way in which this occurs, and how public awareness of the threat is created or intensified, varies considerably through space and over time. This is equally true of the actions with which human societies wish to counter perceived endangerments.

Terminology and concepts such as uncertainty, risk and sustainability have become part of everyday language. This is much less true for the terms vulnerability and resilience. Thus far, the concepts for which both terms stand have been shaped largely by the natural sciences and have been seen in close association with so-called natural hazards.

The contributions to this special issue aim to broaden this discussion. All apply the concepts to fields of activity that represent particularly difficult, even serious challenges for socio-spatial developments. This includes, for instance, the stigmatisation of urban districts, cities and/or regions, but also structural change in old industrial areas. Several papers go a step further by explicitly locating the conceptual pair in socio-scientific discourse. They investigate, on the one hand, the constructivist dimension of vulnerability, i.e. the communicative and social processes within which patterns of perception and interpretation about phenomena and events that should be considered vulnerable are negotiated. And, on the other hand, they investigate the action-related dimension of resilience, i.e. the social practices and coor-

Prof. Dr. H. Kilper $(\bowtie)$

Leibniz-Institut für Regionalentwicklung und Strukturplanung,

Flakenstraße 28-31, 15537 Erkner, Deutschland

e-mail: kilper@irs-net.de dinated actions of subjects and groups connected to such constructed vulnerabilities. This special issue thus aims to stimulate fresh ideas on the extent to which a socio-scientific and spatially-related discourse about vulnerability and resilience could overcome the dichotomy between natural and cultural space, between the material and the non-material, between essentialism and constructivism.

The papers are drawn from the spatial scientific institutes of the Leibniz Association that form the so-called 5R Network, and whose directors function as the editors of the journal "Raumforschung und Raumordnung". The expertise present in these institutions was first brought to print in the "German Annual of Spatial Research and Policy 2010" that was dedicated to the theme "Urban Regional Resilience: How Do Cities and Regions Deal with Change?". The discussion is continued here in a broader circle and with new topics.

The special issue opens with four papers that present theoretically and conceptually oriented deliberations. In their paper Gabriela Christmann and Oliver Ibert concentrate on the dimension of social construction that implies that, even with proven endangerments, actors can develop quite different perceptions of a possible threat and the protective measures that should be taken. They first investigate past research approaches to vulnerability and resilience and then consider Latour's Actor Network Theory, because they have here discovered particularly interesting stimuli for a socio-scientific foundation for vulnerability and resilience. Thilo Lang takes an institutional theoretical perspective in his paper to consider how cities and regions react to socioeconomic crises. His objective is to conceptualise resilience so that it takes the processes and also (institutional) framework conditions of decision-making into account. He sees urban and spatial research based on a social constructivist approach as profiting from resilience research in terms of a 
better understanding of processes of change in complex systems with socio-spatial effects. Swen Zehetmair considers socio-structural aspects of social vulnerability in his paper. He uses the system theory approach of the sociologist Niklas Luhmann as a theoretical basis. Due to the fundamental significance that system theory ascribes to communication in our modern society, Zehetmair considers it a promising approach that can contribute to a better understanding of social vulnerability caused by natural disasters. The paper by Jörn Birkmann, Claudia Bach and Maike Vollmer is also dedicated to the theoretical and conceptual discussion of vulnerability and resilience, although they consistently associate a third term to the conceptual pair, that of adaptation. They use the example of Cologne's vulnerability to flooding to demonstrate the challenges for spatial planning to retain adaptability in the face of changing climatic conditions.

The five papers that then follow take an explicitly social scientific or social constructivist perspective to apply the concept of vulnerability and resilience to various aspects of urban and regional development. Tobias Schmidt presents results from his empirical research into current processes of urban development in Hamburg-Wilhelmsburg and shows how strategies intended to build resilience in a structurally weak urban district initially appear promising for all actors, but can cause counterproductive effects because for a certain group of actors they can lead to new perceptions of vulnerability. The empirical object of the paper by Marc Wolfram and Rico Vogel is urban information infrastructures. When identifying vulnerabilities and agreeing on the design of appropriate countermeasures, it is assumed that information, communication and the emergence of knowledge stand at the centre of interactions between urban actors. These factors are then ascribed a key role. The authors suggest that approaches to the socio-technical constitution of urban information systems should be of central concern to urban actors when attempting to build up urban resilience. Thomas Bürk, Manfred Kühn and Hanna Sommer pursue the question of the extent to which collective spatially based identities are vulnerable to the stigmatisation of cities experiencing structural change. They use the examples of the cities of Sangerhausen and Pirmasens to describe which stigmas are transported into public discourse by national media, how this is perceived in the cities themselves, and what local ways of dealing with the situation are found. Oliver Ibert and Suntje Schmidt have selected an unusual empirical object for their vulnerability analysis: the volatile labour market of musical performers. Using the basis of qualitative interviews they trace the work of construction undertaken by musical performers in terms of their vulnerability and resilience on the employment market. The authors aim thus also to contribute to the spatial analysis of the creative economy. In their paper Gerd Lintz, Peter Wirth and Jörn Harfst apply the conceptual pair vulnerability and resilience to a qualitative case study about the Lusatian Lake District that has recently been experiencing transformation from a brown coal field to a tourist region. They draw attention to the interesting issues that are revealed when the concept of vulnerability and resilience is applied to the analysis of regional development under conditions of uncertainty and far-reaching structural transformations, but also show which conceptual difficulties emerge.

The special issue is brought to a close by the paper by Georg Schiller, Andreas Blum and Martin Behnisch. They firstly develop a concept of "resources efficiency of the built environment", which they then use to present initial ideas about the extent to which the concept of resilience could be appropriate for opening up new perspectives for the further development of an efficiency-oriented view of the built environment.

On behalf of all the editors of the journal, I hope you find this special issue offers stimulating reading and valuable insights. 